\title{
Laboratory observations of transient frictional slip in rock-analog materials at co-seismic slip rates and rapid changes in normal stress
}

\author{
Fuping Yuan ${ }^{\mathrm{b}}$, Vikas Prakash ${ }^{\mathrm{a}, *}$ \\ a Case School of Engineering, Department of Mechanical and Aerospace Engineering, Case Western Reserve University, Cleveland, OH 44106-7222, United States \\ b State Key Laboratory of Nonlinear Mechanics, Institute of Mechanics, Chinese Academy of Sciences, Beijing 100190, China
}

\section{A R T I C L E I N F O}

Article history:

Received 18 January 2012

Received in revised form 4 June 2012

Accepted 19 June 2012

Available online 28 June 2012

\section{Keywords:}

Rock-analog materials

Co-seismic slip rates

Rate weakening and strengthening

Flash heating

Rapid change in normal stress

Plate-impact pressure-shear friction

experiments

\begin{abstract}
A B S T R A C T
Knowledge of frictional (shear) resistance and its dependency on slip distance, slip velocity, normal stress, and surface roughness is fundamental information for understanding earthquake physics and the energy released during such events. In view of this, in the present study, plate-impact pressure-shear friction experiments are conducted to investigate the frictional resistance in a rock analog material, i.e. soda-lime glass, under interfacial conditions of relevance to fault rupture. The results of the experiments indicate that a wide range of frictional slip conditions exist at the slip interface ranging from initial no-slip and followed by slip weakening, slip strengthening (healing), and seizure all during a single slip event. The slip-weakening phase is understood to be most likely due to thermal-induced flash heating and incipient melting at asperity junctions, while the slip strengthening (slip-healing) phase is understood to be a result of coalescence and solidification of local melt patches on the slip interface. In addition, plate impact pressure-shear normal-stress change (drop) experiments are employed to probe the response of the slip interface due to sudden alterations in normal stress. In particular, the location (timing) of the stress drop is varied so as to investigate the behavior of the slip interface in its slip-weakening, slip-strengthening (healing) phase, or the seized phase, in response to sudden drop in normal stress. These experimental results provide a rich set of data to better understand the range of possible friction slip states that can be achieved and/or critically examine existing dynamic friction models for fault slip behavior.
\end{abstract}

(c) 2012 Elsevier B.V. All rights reserved.

\section{Introduction}

Determination of co-seismic slip resistance along earth faults is critical for understanding the magnitude of friction-stress reduction and hence the near-fault acceleration that can occur during earthquakes. Friction at constant normal stress and sliding speeds of less than $1 \mathrm{~mm} / \mathrm{s}$ has been studied extensively for a wide range of materials. The characterization of these results in terms of rate-and-state variable friction laws has allowed a better understanding of a wide variety of aspects of the mechanics of earthquakes (Beeler et al., 1994; Blanpied and Tullis, 1986; Blanpied et al., 1998; Dieterich, 1979, 1981; Dieterich and Conrad, 1984; Dieterich and Linker, 1992; Hong and Marone, 2005; Kilgore et al., 1993; Marone, 1998; Marone et al., 1990; Okubo and Dieterich, 1986; Ruina, 1980, 1983; Scholz, 1998; Scholz et al., 1972; Tullis, 1988; Tullis and Weeks, 1986), including, for example, what to expect in terms of premonitory slip and Omori's Law for aftershock decay (Scholz, 2002).

Experimental data suggest that frictional resistance in geo-materials at slip speeds $\leq 1 \mathrm{~mm} / \mathrm{s}$ and slip distances of less than $1 \mathrm{~mm}$ is high

\footnotetext{
* Corresponding author. Tel.: +1216368 6440 .

E-mail addresses: fpyuan@Inm.imech.ac.cn (F. Yuan), vikas.prakash@case.edu (V. Prakash).
}

with $\mu \sim 0.6$ to 0.85 (Byerlee, 1978; Dieterich, 1978; Dieterich and Kilgore, 1996). However, seismic inversions provide evidence that frictional resistance of major faults at co-seismic slip speeds ( 1 to $5 \mathrm{~m} / \mathrm{s}$ ) may be quite low (Brune, 1970); recently, data at high slip rates and large slip displacements suggest that frictional behavior at these slip speeds is dramatically different and that dynamic slip and slip-rate weakening occurs (Brantut et al., 2008; Di Toro et al., 2004, 2006, 2011; Fukuyama and Mizoguchi, 2010; Kitajima et al., 2011; Mizoguchi et al., 2009; Rice, 2006; Sone and Shimamoto, 2009; Tsutsumi and Shimamoto, 1997; Yuan and Prakash, 2008a; Yuan and Prakash, 2008b).

In this regard, Rice (1999, 2006), Rempel and Weaver (2008), and Beeler et al. (2008) have summarized flash heating and consequent weakening at highly stressed asperity contacts during rapid slip, which reduces the friction coefficient, a phenomenon studied for many years as the key of understanding the slip rate dependence of dry friction in metals at high slip rates (Archard, 1958; Ashby et al., 1991; Barber, 1976; Bowden and Thomas, 1954; Ettles, 1986; Irfan and Prakash, 1994; Kuhlmann-Wilsdorf, 1985; Lim and Ashby, 1987; Lim et al., 1989; Molinari et al., 1999; Okada et al., 2001; Prakash, 1995; Yuan et al., 2009), and which has also been considered recently in seismology as a mechanism that could be active in controlling fault friction during seismic slip before macroscopic melting occurs. For sufficiently large combinations of slip speeds and effective normal stress, 
thermal power generated during solid-on-solid slip overwhelms the ability of thermal conduction to carry the frictional heat away from the slip interface and macroscopic melting may occur (Di Toro et al., 2006, 2011; Hirose and Shimamoto, 2005; Liou et al., 2004; Nielsen et al., 2010; Niemeijer et al., 2011; Okada et al., 2001; Okada et al., 2002; Spray, 2005; Tsutsumi and Shimamoto, 1997). Since molten layers have a low viscosity, they may lead to hydrodynamic lubrication of faults reducing dynamic friction.

In a recent study, Sone and Shimamoto (2009) presented results of experiments aimed at understanding the frictional behavior of fault zone materials under variable slip rates, a condition that is more representative of natural earthquakes. Their results indicate that faults undergo a sequence of strengthening, weakening and healing, during a typical acceleration and deceleration slip event. They explained such a sequence by extrapolation of the rate-and-state frictional behavior at low slip velocities to more realistic slip rates, but involving different physical mechanisms and a different scale. The initial strengthening is understood to impose a barrier for rupture growth into large earthquakes, while healing during the deceleration phase was understood to lead to pulse-like earthquake ruptures (Beeler and Tullis, 1996; Cochard and Madariaga, 1994; Heaton, 1990; Lapusta and Rice, 2003; Noda et al., 2009; Perrin et al., 1995; Zheng and Rice, 1998) and static stress drops that are low in comparison with the dynamic stress changes.

In addition to understanding the evolution of frictional slip resistance during rapid sliding on a fault at constant normal stress, knowledge of effects of rapid changes in normal stress on the frictional strength is important since during seismic slip there can be abrupt changes in normal stress. For example, slip on non-planar faults and/or on faults in heterogeneous materials can induce changes in normal stress, leading to complex time history of fault friction (Andrews and Ben-Zion, 1997; Harris and Day, 1997; Harris et al., 1991). Rupture propagation at fault bends, step-overs, and branch points are other examples of geometrical features that can lead to changes in normal stress and may affect rupture extent and speed along faults (Kame et al., 2003; Poliakov et al., 2002). In addition, theoretical studies of slip at dissimilar material interfaces (Adams, 1995; Weertman, 1980) have shown that spatially inhomogeneous slip can result in an alteration in normal stress (Andrews and Ben-Zion, 1997; Ben-Zion, 2001; Cochard and Rice, 2000; Ranjith and Rice, 2001; Simões and Martins, 1998).

To date, there remains conflicting evidence on the effects of abrupt changes in normal stress on frictional strength. Conventional slow friction studies, with much less abrupt change of normal stress (Boettcher and Marone, 2004; Dieterich and Linker, 1992; Hong and Marone, 2005; Linker and Dieterich, 1992; Olsson, 1988), suggest that shear strength changes on the same time-scale as the normal stress change, but changes only partly towards what it will ultimately evolve to after a few $\mu \mathrm{m}$ of further slip. This instantaneous response observed in the experiments by Linker and Dieterich (1992) and others, has been attributed to a machine effect, that is, an unwanted elastic coupling of friction (shear) stress to the normal stress and is thought to result from slight misalignment of the loading frame or differential Poisson expansion across the fault surface as the fault normal stress is changed. In contrast, precise laser-based diagnosis of oblique shock wave experiments at slip rates of order $10 \mathrm{~m} \mathrm{~s}^{-1}$ involving abrupt normal stress changes by a reflected sharp shock front (Prakash, 1998; Prakash and Clifton, 1993) suggests that there is no corresponding abrupt change in shear strength, but only an evolution with continuing slip (over a few $\mu \mathrm{m}$ scale). In other words, the entire response of shear stress to a rapid normal stress change is slow and there is an absence of the instantaneous response.

Jim Rice and his colleagues have suggested, on the basis of experimental measurements (shock loading for Prakash (1998) versus near quasi-static conditions for Linker and Dieterich (1992)), that Prakash's observations may be more appropriate for models of dynamic rupture despite those measurements being on bi-material interfaces of tungsten carbide and stainless steel or titanium rather than rock (Ranjith and Rice, 2001). They found the Linker and Dieterich (1992) formulation to be problematic, when used in models of dynamic fault slip between dissimilar materials. In fact, it has been established that deviations from the classical formulation of Coulomb friction, of a type seen in shock wave experiments which deliver an abrupt change in normal stress to a slipping surface (Prakash, 1998; Prakash and Clifton, 1993), allow models of rupture along dissimilar material interfaces to be well posed mathematically, while the classical formulation is not well posed in that circumstance (Cochard and Rice, 2000; Noda et al., 2009; Ranjith and Rice, 2001; Rice, 2006; Rice and Cocco, 2007; Rice et al., 2001). In reality, rupture of a fault separating dissimilar materials is affected by both the effect of coupling slip to alteration of normal stress and the effect of weakening of friction with slip rate or slip that would exist for a fault between identical materials. Both effects are important for a complete computational and experimental description of rupture along dissimilar material interfaces (Harris and Day, 1997; Xia et al., 2005).

To-date, a majority of the high slip-rate friction experiments have utilized a rotary shear type friction apparatus to obtain the evolution of friction stress at a constant prescribed slip velocity. However, in these high slip velocity experiments prescribing a constant slip velocity has remained problematic, since the weakening of friction starts to occur when the slip velocity increases from zero (or very small value) to the desired velocity, and how the apparatus accelerates the slip to the target velocity affects the slip weakening of the friction inferred from the experimental results (Fukuyama and Mizoguchi, 2010). Another associated concern with the use of the high speed rotary shear apparatus has been the onset of specimen melting during a typical rotary shear test at relatively low normal stresses. This has primarily been due to the relatively large slip attained in these experiments, which is difficult to control with precision because of machine inertia, especially during the acceleration and deceleration phase of the test apparatus. While introducing additional wear mechanisms, the melting of the specimen makes interpretation of the experimental results more difficult when compared to the friction data in the pre-melt regime. These effects are amplified when relatively high normal stresses or high slip velocities are employed in the experiments. Another important limitation of the rotary shear experiment is to do with the very nature (time-scales and diagnostics) of the rotary shear tests in that they preclude investigation of transient frictional phenomena that arise due to interaction of stress waves with the propagating rupture plane/front, which are known to substantially alter the stress state during rupture propagation.

In the present study, a series of plate-impact pressure-shear friction experiments is conducted to investigate frictional resistance in rock analog materials. The primary objective of these experiments is to investigate the frictional resistance of relevant rock-analog materials, e.g. soda-lime glass, at co-seismic slip speeds and higher, so as to better understand the role of high slip speeds in controlling slip and slip-rate weakening by the mechanism of asperity flash heating and associated thermal softening at the slip interface. In these experiments the combined normal and shear loading at the frictional interface is achieved by the use of pressure and shear waves at the slip interface. Since the flyer and the target plates (comprising the tribo-pair) are designed to remain elastic during impact, critical frictional slip parameters, such as, the friction stress, normal stress, slip velocity and slip at the slip interface can be obtained by using principles of elastodynamic theory (Achenbach, 1973). A noteworthy feature of the experiments is that they provide highly time resolved measurements of the effects of slip and slip-rates on the evolution of friction stress prior to the development of macroscopic melt at the frictional interface at normal stresses as high as ca. $1 \mathrm{GPa}$. This condition is facilitated by the relatively short window times, which are characteristic of plate impact experiments, and permit slip 
distances of only a fraction of a mm during the experiment. Another attractive feature of the experiments is that the slip and/or slip velocity history during the loading of the frictional interface, does not have to be prescribed a priori and the evolution of slip and slip rates are governed by the inherent frictional characteristics of the slip interface. In addition, besides providing fundamental frictional data at constant normal stress, these experiments can easily be modified to introduce sudden alterations in normal stress during the slip process. This is facilitated by the fact that the short rise-time (of the order of a few tens of nanoseconds) of the pressure and shear waves employed in the experiments, which allows rapid changes in friction state at the slip interface to be introduced with appropriate design of the experiments. In this way, the results of these experiments will be relevant not just for investigation of mechanisms of dynamic fault weakening at constant normal stress, but also provide data to critically examine the structure of rate and state dependent dynamic friction models of earthquake rupture in situations where rapid changes in normal stress are encountered. To the best of authors' knowledge this paper is the first to report such effects of rapid alteration in normal stress on the evolution of friction stress in rock-analog materials.

\section{Pressure shear plate impact friction experiments}

In the present study a series of plate-impact pressure-shear friction experiments is conducted on soda-lime glass at constant normal stress and with normal stress alterations at the slip interface. The choice of soda-lime glass was dictated by a number of previous studies (Dieterich and Kilgore, 1994, 1996; Weeks et al., 1991), which have shown that the frictional behavior of glass is almost identical to that of cohesive samples of silicate-built rocks (e.g., gabbro, tonalite, peridotite, monzodiorite, novaculite). Also, since soda-lime glass is essentially an isotropic material, its use as a model material to study frictional response in cohesive silicate-rich geo-materials avoids complications of wave scattering and dispersion from heterogeneities inherent in the microstructure of natural rocks in the interpretation of friction data from the measured particle-velocity versus time profiles.

Since we are interested in mechanisms that control slip and slip-rate weakening including the role of flash heating as well as nucleation and growth of thermally-softened/melt patches during high-rate slip event, the thermo-mechanical properties of soda lime glass, including its glass-transition and solidus to liquidus transition temperatures are particularly important. In this regard, the glass transition temperature $T_{g}$, of soda-lime glass is reported to be $570{ }^{\circ} \mathrm{C}$ while the solidus to liquidus temperature is $\sim 1000{ }^{\circ} \mathrm{C}$ (Mazurin, 1993). As discussed in more detail in Section 3 of this paper, this temperature range is easily accessible by using soda lime glass in conjunction with the plate impact friction experiments.

\subsection{Experimental configuration}

In this section, details of the plate impact pressure shear friction configuration and specimen preparation are provided. The pressure-shear friction experiments were conducted using the $82.5 \mathrm{~mm}$ bore single-stage gas gun facility at Case Western Reserve University. The schematic of the experimental configuration is shown in Fig. 1(a). A fiberglass projectile carrying the flyer plate is accelerated down the gun barrel by means of compressed air. The rear end of the projectile has sealing O-ring and a Teflon key that slides in a key-way inside the gun barrel to prevent any rotation of the projectile. In order to reduce the possibility of an air cushion between the flyer and target plates, impact takes place in a target chamber that has been evacuated to $50 \mu \mathrm{m}$ of $\mathrm{Hg}$ prior to impact. The vacuum helps to eliminate the air cushion between the flyer and the front target plate at the time of impact. This is essential since the presence of air cushion in between the flyer and the target plates can possibly introduce, (a) a finite rise time
A

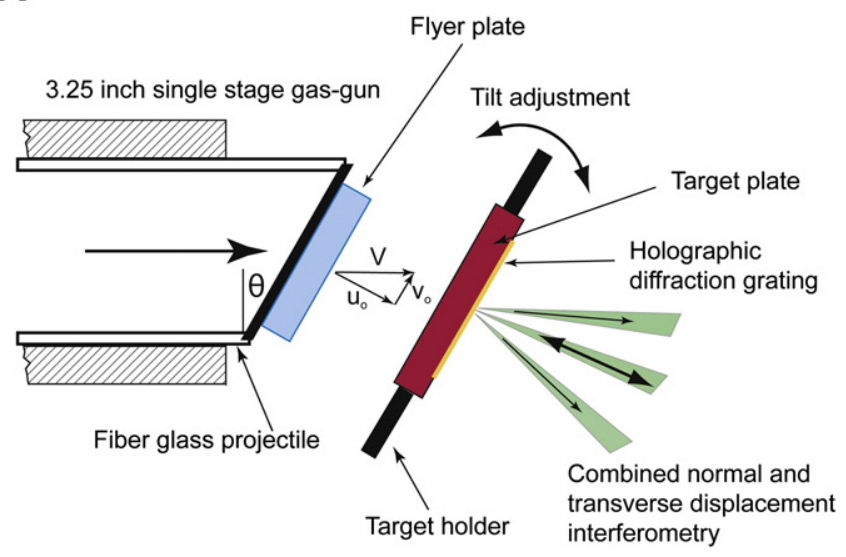

B
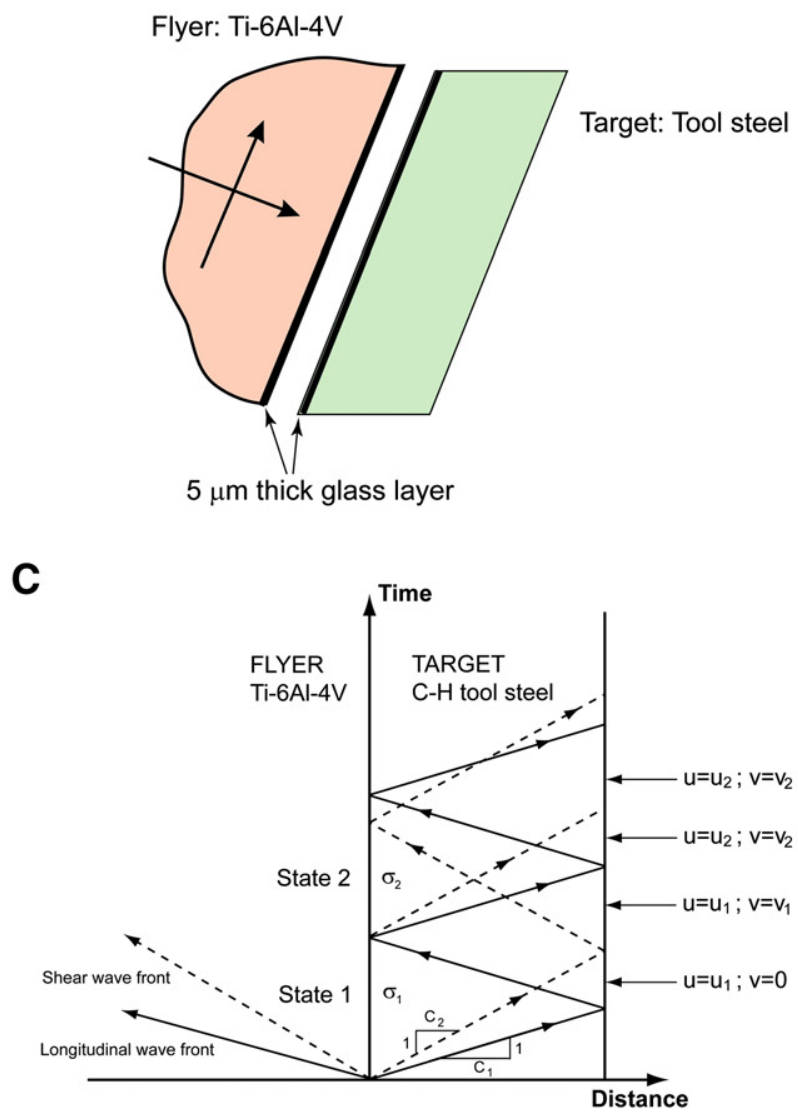

Fig. 1. (A) Schematic of the plate-impact pressure-shear friction experiment; (B) experimental configuration for soda-lime glass-on-glass impact; $(C)$ wave propagation in flyer and target plates: time versus distance diagram.

in the stress pulse generated during impact, and (b) may cause slip at the flyer-target plate interface during the pressure-shear impact loading. To ensure the generation of plane waves with wave-front sufficiently parallel to the impact face, the flyer and the target plates are carefully aligned to be parallel to within $2 \times 10^{-5}$ rad by using an optical alignment scheme developed by Kumar and Clifton (1977). Impact is designed to occur at an angle $\theta$ relative to the direction of approach. This results in pressure-shear loading at the flyer-target (tribo-pair) interface.

During the experiment the time history of the normal and transverse components of the particle velocity at the rear surface of the target-plate is measured by using time-resolved laser-based diagnostics. The measurements of particle velocity are restricted to the time 
interval prior to the arrival of the unloading waves from the lateral boundary of the specimen. In view of this, during the time interval of interest, the flyer and the target plates can be considered to be essentially infinite in their spatial dimension and the configuration be modeled as a semi-infinite half plane impacting on another. This simplification in test geometry along with the control of projectile velocity allows one-dimensional elastic wave theory to be used in obtaining the normal and shear tractions, slip-velocity and temperature at the tribo-pair interface. By controlling the skew angle $\theta$ and the impact velocity a variety of friction states (with normal stress varying from $200 \mathrm{MPa}$ to $1 \mathrm{GPa}$ and slip speeds from no-slip to $30 \mathrm{~m} / \mathrm{s}$ ) can be readily obtained. Other details regarding the experimental configuration and execution of the experiments can be found elsewhere (Liou et al., 2004; Okada et al., 2001; Prakash, 1995, 2009; Ullah et al., 2007; Yuan and Prakash, 2008a; Yuan et al., 2009).

\subsection{Tribo-pair materials and design of the pressure-shear experiments}

In order to investigate the dynamic frictional response of glass versus glass slip, thin films of soda-lime glass ( $5 \mu \mathrm{m}$ in thickness) were deposited on the impacting faces of the flyer and target plates comprising Ti-6Al-4V and $\mathrm{CH}$ tool-steel, respectively (Fig. 1(b)). The thin glass films were deposited by Thin-Films Research, Inc., Westford, MA, by employing a chemical vapor deposition procedure. Given the relatively high elastic wave speeds of longitudinal and transverse waves in glass, the ca. $5 \mu \mathrm{m}$ thickness of the glass film is expected to preclude any significant wave dispersion effects at the metal/glass interfaces. In all experiments the impact velocity of the flyer plate is controlled such that the flyer and target plates remain elastic during impact. This condition ensures that linear elastodynamic theory could be used to calculate the normal and shear tractions as well as the slip velocity at the frictional interface from the measurements of the transverse component of the particle velocity at the free surface of the target plate.

The thickness of the flyer and the target plates are designed such that the time for longitudinal wave propagation through the thickness of the flyer plate is greater than the corresponding round-trip time of the longitudinal wave in the target plate. Under these conditions, when the longitudinal wave reflected from the rear surface (free surface) of the target plate arrives at the target/flyer interface, the normal stress at the frictional interface is changed abruptly. Since the longitudinal impedance of the flyer plate (Ti-6Al-4V) is less than the longitudinal impedance of the target plate $(\mathrm{CH}$ tool-steel), the arrival of the longitudinal release wave at the slip interface results in a drop in the interfacial normal stress.

The wave propagation in the target and flyer is illustrated schematically in the time-distance diagram shown in Fig. 1(c). The abscissa represents the spatial position of the wave front at any particular time and the ordinate represents the temporal location of the wave front. At impact, both longitudinal and shear waves are generated at the tribo-pair interface and travel through the thickness of the flyer and the target plates. The longitudinal wave fronts are represented by solid lines and the shear wave fronts are represented by dashed lines. The slope of the solid line represents the inverse of the longitudinal wave speed and the slope of the dashed line represents the inverse of the shear wave speed in the material. In State 1 the tribo-pair interface is under a constant normal stress $\sigma_{1}$, and thus allows investigation of dynamic sliding characteristics of the frictional interface under constant normal stress. Upon reflection of the compressive wave at the rear (free) surface of the target plate, an unloading (release) wave is generated, which propagates back towards the tribo-pair interface. When this unloading wave arrives at the frictional interface it reduces the applied normal stress from $\sigma_{1}$ to $\sigma_{2}$. The corresponding friction stress is denoted by $\tau_{1}$ and $\tau_{2}$, respectively. The new frictional state is called State 2, and allows the investigation of dynamic sliding characteristics of the frictional interface subjected to abrupt changes in normal stress.

2.3. Wave analysis of pressure-shear friction experiments on soda-lime glass: calculation of interfacial tractions, slip velocity, and temperature

Using the method of characteristics for 1-D hyperbolic wave equations the normal and transverse components of interfacial traction, slip velocity, and the slip displacement can be related to the normal and transverse components of particle velocity of the free surface of the target plate, $u_{f s}(t)$ and $v_{f s}(t)$, respectively, and the shear and longitudinal impedances of the flyer and the target materials (Achenbach, 1973).

\subsubsection{State 1}

Before impact the flyer and the target plates are unstressed. The target is held stationary while the flyer is accelerated and impacts the target at a measured velocity $V$. From the knowledge of the angle of inclination $\theta$ of the projectile, the initial normal and transverse particle velocities $u_{o}$ and $v_{o}$, respectively, of the flyer plate are given by $u_{o}=V \cos \theta$ and $v_{o}=V \sin \theta$, respectively.

When the flyer impacts the target, both the normal and transverse components of velocity are imposed on the impact face of the target. A longitudinal compression stress wave with wave speed $c_{1}$ and a shear stress wave with a wave speed $c_{2}$ propagate into the flyer and the target plates. From one-dimensional analysis of the governing hyperbolic partial differential equations the stress and the particle velocity relations, which hold along the characteristics, are given by Prakash and Clifton (1993)

$$
\begin{aligned}
& \sigma \pm\left(\rho c_{1}\right) u=\text { constant; along } \frac{d x}{d t}=\mp c_{1} . \\
& \tau \pm\left(\rho c_{2}\right) v=\text { constant; along } \frac{d x}{d t}=\mp c_{2} .
\end{aligned}
$$

In Eqs. (1) and (2), $\sigma$ and $\tau$ are the normal and shear stresses, $u$ and $v$ are the normal and transverse components of the particle velocity, $\rho$ is the mass density, and $\left(\rho c_{1}\right)$ and $\left(\rho c_{2}\right)$ are the longitudinal and shear impedance, respectively.

Using initial conditions the components of traction at the interface between the flyer and the target can be expressed as

$\tau(t)=-\frac{\left(\rho c_{2}\right)_{t}}{2} v_{f s}(t)$

$\sigma(t)=\frac{\left(\rho c_{1}\right)_{t}}{2} u_{f s}(t)$

where, $v_{f s}(t)$ and $u_{f s}(t)$ are the transverse and the normal particle velocities at the rear surface of the target plate, and the subscripts $f$ and $t$ refer to the flyer and the target plates, respectively.

When slip occurs at the flyer-target interface, the measured free surface velocity of the target plate can be used along with Eqs. (3) and (4) to obtain the coefficient of kinetic friction

$\mu_{\mathrm{k}}(t)=\left|\frac{\tau}{\sigma}\right|$

From the knowledge of the impact velocity $V$, the skew angle $\theta$, the shear impedances of the flyer and the target plates, and the measured free-surface transverse velocity $v_{f s}(t)$, the slip velocity can be expressed as

$V_{\text {slip }}=V \sin \theta-\left[\frac{\left(\rho c_{2}\right)_{t}+\left(\rho c_{2}\right)_{f}}{2\left(\rho c_{2}\right)_{f}}\right] V_{f s}(t)$. 
The accumulated slip distance can be obtained from Eq. (6) by integrating the slip velocity in time

$\delta_{\text {slip }}=\int_{0}^{t} V_{\text {slip }}(t) d t$

Moreover, under conditions of no slip the free surface particle velocities of the rear surface of the target plate are related to the flyer velocity by

$u_{f s}=\frac{2\left(\rho c_{1}\right)_{f}}{\left[\left(\rho c_{1}\right)_{t}+\left(\rho c_{1}\right)_{f}\right]} V \cos \theta$

$v_{f s}=\frac{2\left(\rho c_{2}\right)_{f}}{\left[\left(\rho c_{2}\right)_{t}+\left(\rho c_{2}\right)_{f}\right]} V \sin \theta$.

\subsubsection{State 2}

When the compressive longitudinal wave reflects from the free surface of the target plate it reduces the compressive normal stress at the interface from $\sigma_{1}$ to $\sigma_{2}$

$\sigma_{2}=\frac{\left[\left(\rho c_{L}\right)_{f}-\left(\rho c_{L}\right)_{t}\right]}{\left[\left(\rho c_{L}\right)_{f}+\left(\rho c_{L}\right)_{t}\right]} \sigma_{1}$.

For the Ti6Al4V/CH tool-steel tribo-pair employed in the present study the ratio $\sigma_{2} / \sigma_{1} \sim 0.25$.

The corresponding expressions for the friction stress and slip velocity are obtained by solving the characteristic relations for State 2, and can be expressed as

$\tau_{2}(t)=-\frac{\left(\rho c_{2}\right)_{t}}{2} v_{b}(t)$

and

$V_{2}^{s l i p}=V \sin \theta-\left[\frac{\left(\rho c_{2}\right)_{t}+\left(\rho c_{2}\right)_{f}}{2\left(\rho c_{2}\right)_{f}}\right] v_{b}(t)$.

\subsection{Bulk temperature at the tribo-pair interface}

The bulk temperature rise at the tribo-pair interface is estimated by solving the following one dimensional transient heat conduction equation

$\frac{\partial^{2} T}{\partial x^{2}}=-\frac{\partial T}{\partial t}$

With the initial condition

$\mathrm{T}(\mathrm{x}, 0)=0$,

and the boundary conditions

$-k \frac{\partial T}{\partial x}(x=0, t)=\dot{q}(t)$

$T(x=\infty, t)=0$.

In Eqs. (13) to (16) $T$ is the temperature rise, $k$ is the thermal conductivity, $\alpha$ is the thermal diffusivity and $x$ represents the distance perpendicular to the interface. Table 1 provides a summary of thermal properties of soda-lime glass. Using Eqs. (13) to (16) the temperature rise distribution as a function of time and position can be obtained as

$T(x, t)=\frac{1}{k} \int_{0}^{t} \dot{q}(\xi) \frac{\sqrt{\alpha}}{\sqrt{\pi(t-\xi)}} \exp \left(\frac{-x^{2}}{4 \alpha(t-\xi)}\right) d \xi$.

In order to calculate the temperature distribution in the tribo-pair, an estimate for the heat source $\dot{q}(t)$ is required. Using the experimentally measured friction stress $\tau$, and the slip velocity $V_{\text {slip }}$, the heat generated at the interface can be estimated to be

$\dot{q}_{\text {flyer }}(t)=0.5 \times \tau(t) V_{\text {slip }}(t)$.

In the present plate impact friction experiments the thickness of the soda lime glass was selected to be $5 \mu \mathrm{m}$. Besides alleviating complications due to wave dispersion and scattering, the $5 \mu \mathrm{m}$ thickness ensures that the temperature gradient normal to the frictional interface in the flyer and target plates resides entirely in the soda lime glass films, and the flyer and target plates remain essentially at the ambient temperature during the entire duration of the experiment. This point can be understood more clearly from Figs. 2c, 3c and 4c, which show that temperature rise at distances greater than $4 \mu \mathrm{m}$ away from the slip interface is essentially negligible. This condition leads to a considerable simplification in modeling temperature rise at the frictional interface, in which the soda lime glass films can be modeled as one semi-infinite half plane sliding on another and the two metal plates (substrates) can be ignored from the thermal model.

\section{Experimental results}

Table 2 provides a summary of the plate-impact pressure-shear friction experiments on soda-lime glass conducted in the present study. In all experiments, except for Shot 1 , a skew angle of $35^{\circ}$ was utilized to promote high slip speeds. For Shot 1 a skew angle of $30^{\circ}$ was used. The root mean square (rms) surface roughness of the impacting surfaces of the flyer and target plates was maintained at $\sim 0.2 \mu \mathrm{m}$ for Shots 1 and 2, while for Shot 3 the roughness was $0.12 \mu \mathrm{m}$. The projectile (impact) velocities for Shots 1, 2, and 3 were $77.3 \mathrm{~m} / \mathrm{s}, 48.4 \mathrm{~m} / \mathrm{s}$, and $54.3 \mathrm{~m} / \mathrm{s}$, respectively. At these impact velocities the bulk of the flyer and the target plates are expected to remain essentially elastic during the experiment.

As discussed in Section 2, for the glass-on-glass friction experiments conducted in the present study the impedance mismatch between the flyer (Ti6Al4V) and the target (tool-steel) plates result in a drop in normal stress at the slip interface. As determined from Eq. (10), the normal stress in the new state (State 2 ) is approximately 0.25 times the normal stress in the state prior to the drop in normal stress (State 1). It must be noted that the thicknesses of the flyer and target plates are similar for Shots 1 and 2 but are quite different for Shot 3. The thickness of the Ti-6Al-4V flyer plate in Shot 3 is $13.1 \mathrm{~mm}$ when compared to just $8 \mathrm{~mm}$ for Shots 1 and 2 . This larger thickness of the Ti-6Al-4V flyer in Shot 3 results in a much longer time for the longitudinal release wave to return back from the rear (free) surface of the flyer plate to the slip interface and drop the interfacial normal stress. This control over the arrival time of the release wave at the slip interface allows us to investigate the response of the interface subjected to abrupt changes in the normal stress at different stages in the interface weakening and strengthening phases. For Shots 1 and 2, the normal stress drop is designed to occur prior

Table 1

Summary of thermal properties of soda-lime glass.

\begin{tabular}{lll}
\hline Materials & Thermal conductivity $k,(W / m . K)$ & Thermal diffusivity $\alpha, m^{2} / s$ \\
\hline Soda-lime glass & 1.38 & $0.891 \times 10^{-6}$ \\
\hline
\end{tabular}


A

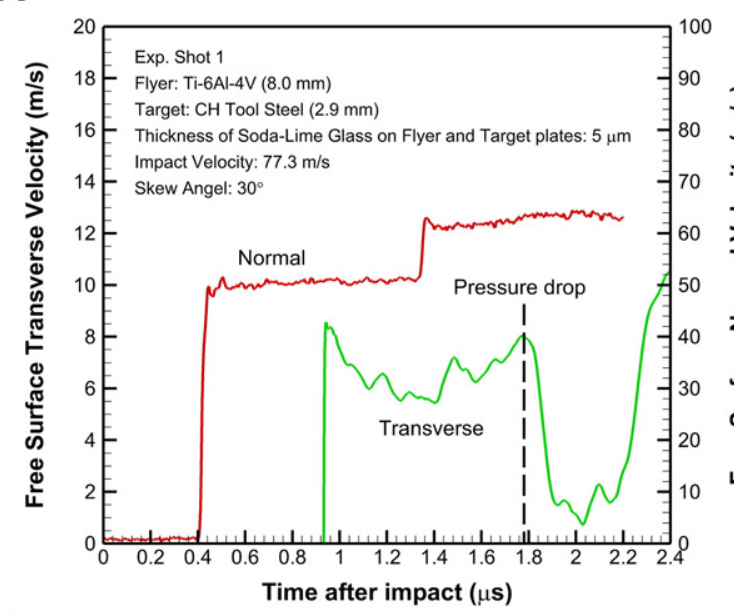

C

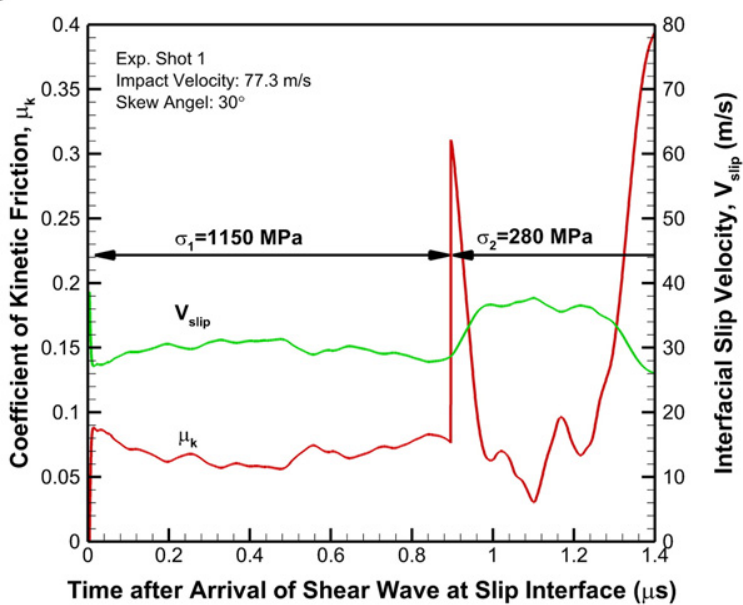

B

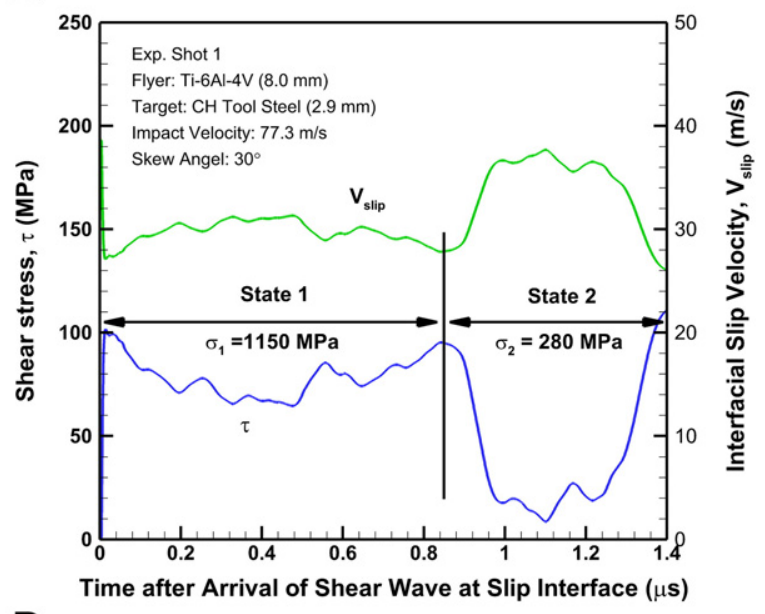

D

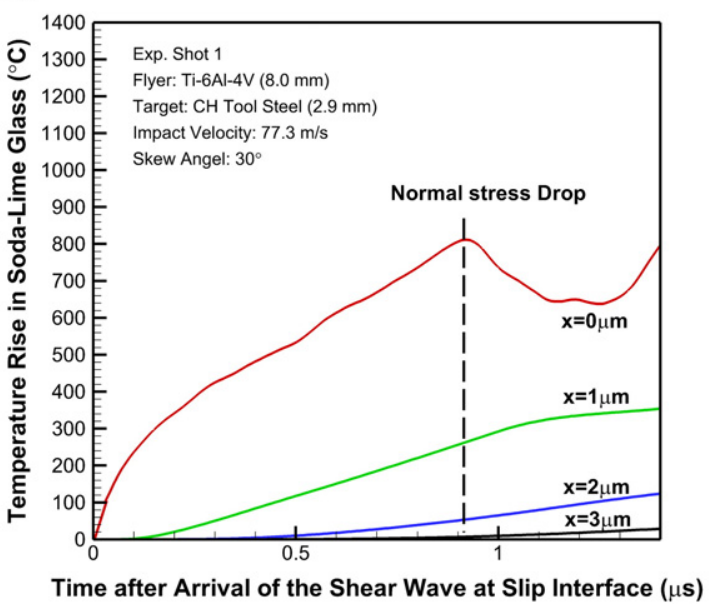

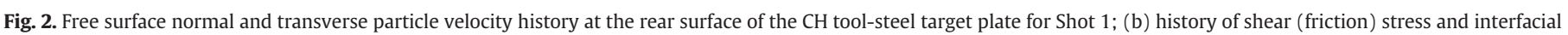
slip velocity for Shot 1 ; (c) history of interfacial slip velocity and coefficient of kinetic friction for Shot1; (d) estimated temperature rise at the tribo-pair interface for Shot 1.

to the strengthening phase while for Shot 3 the normal stress drop occurs when the interface has essentially seized (no slip), i.e., after the weakening and strengthening phases. This point will be discussed in more detail while discussing the results of the three experiments.

The experimental results for Shot 1 are shown in Fig. 2(a) to (d). The experiment was conducted at an impact velocity of $77.3 \mathrm{~m} / \mathrm{s}$ and at a skew angle of $30^{\circ}$. Fig. 2(a) shows the measured normal and transverse components of the particle velocity history at the free surface of the $\mathrm{CH}$ tool-steel target plate. The abscissa represents the time after impact. The normal and transverse components of the particle velocity histories at the rear surface of the target plate were obtained by using laser-based diagnostics in which a multi-beam Velocity Interferometer System for Any Reflector (VISAR) was adapted to provide a robust transverse displacement interferometer (Yuan and Prakash, 2008a; Yuan et al., 2009). At the arrival of the longitudinal wave at the free surface of the target plate the normal component of the particle velocity jumps to about $50 \mathrm{~m} / \mathrm{s}$ at ca. $400 \mathrm{~ns}$. The second abrupt rise in the normal component of the particle velocity occurs at ca. $1234 \mathrm{~ns}$, which is coincident with the arrival of the reflected wave from the rear surface of the steel target plate at the slip interface. The arrival of shear wave at the free surface of the target plate occurs at $930 \mathrm{~ns}$. At the arrival of the shear wave the transverse component of the free-surface particle velocity jumps to $8.3 \mathrm{~m} /$ $\mathrm{s}$, which is much below $25.9 \mathrm{~m} / \mathrm{s}$, which is the predicted transverse velocity for no-slip at the slip interface (estimated by using Eq. (6) with $V_{\text {slip }}$ on the LHS set to zero). After a momentary stay at this level, the transverse particle velocity falls rapidly to about $6 \mathrm{~m} / \mathrm{s}$ before increasing again to $8 \mathrm{~m} / \mathrm{s}$. At the arrival of the unloading longitudinal wave at the slip interface (which results in the drop in normal stress), the transverse particle velocity falls precipitously to a level of about $1 \mathrm{~m} / \mathrm{s}$.

Fig. 2(b) shows the corresponding friction stress, $\tau$, and slip velocity, $V_{\text {slip }}$, as a function of time for the Shot 1 . Two distinct friction states are obtained in the experiment: State 1, which begins at the arrival of the shear wave at the slip interface and ends when the unloading longitudinal wave arrives at the interface at $875 \mathrm{~ns}$, and State 2 which ends at ca. 1300 ns. The corresponding normal stresses at the slip interface are $1150 \mathrm{MPa}$ and $280 \mathrm{MPa}$, respectively. The normal stress levels in States 1 and 2 were obtained from the normal components of the free-surface particle velocity by using the 1-D elastic wave theory presented in Section 2.3, and as given by Eqs. (4) and (10). During State 1, the interface shows rapid slip and slip velocity weakening during which the shear stress at the interface falls from $100 \mathrm{MPa}$ to $68 \mathrm{MPa}$. The slip velocity during this time increases from $27 \mathrm{~m} / \mathrm{s}$ to $32 \mathrm{~m} / \mathrm{s}$. The weakening phase is followed by a distinct strengthening phase, during which the shear stress increases from $68 \mathrm{MPa}$ to approximately $97 \mathrm{MPa}$ with the slip velocity falling from $32 \mathrm{~m} / \mathrm{s}$ to $28 \mathrm{~m} / \mathrm{s}$. The arrival of unloading longitudinal wave results in an abrupt drop in normal stress at the slip interface and signals the beginning of State 2. The drop in normal stress results 
A

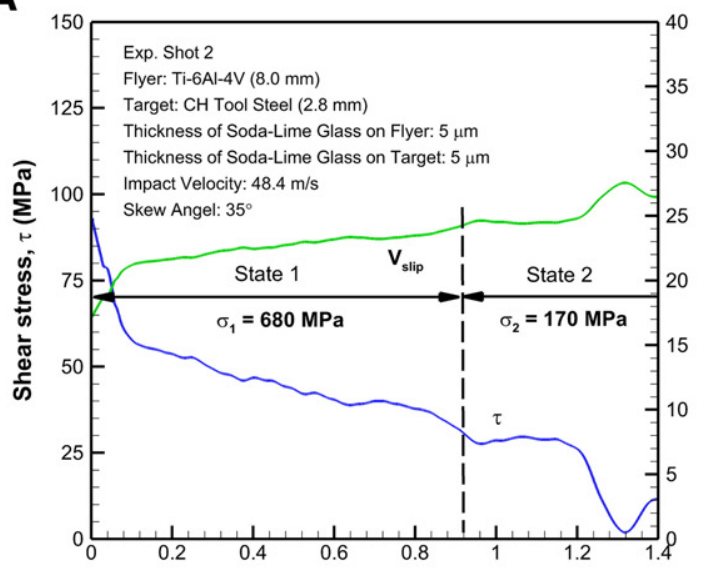

Time after Arrival of Shear wave at Slip Interface ( $\mu$ s)

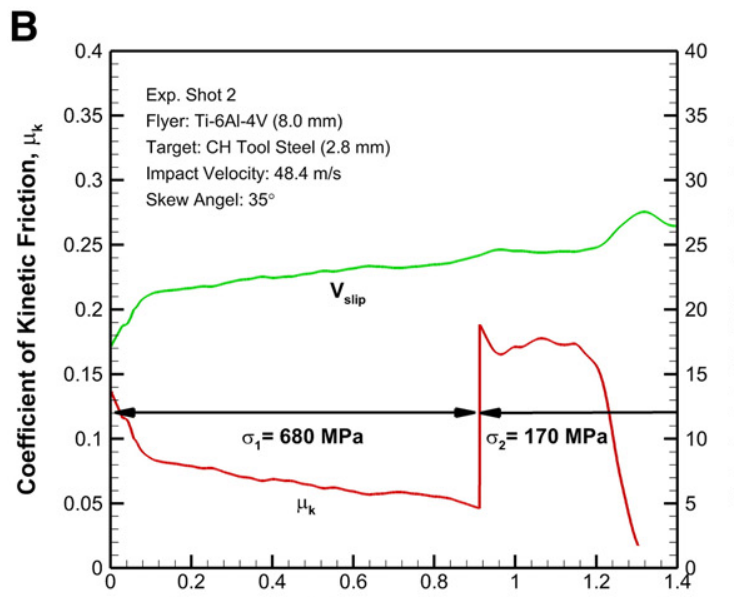

Time after Arrival of Shear Wave at Slip Interface $(\mu \mathrm{s})$

\section{C}

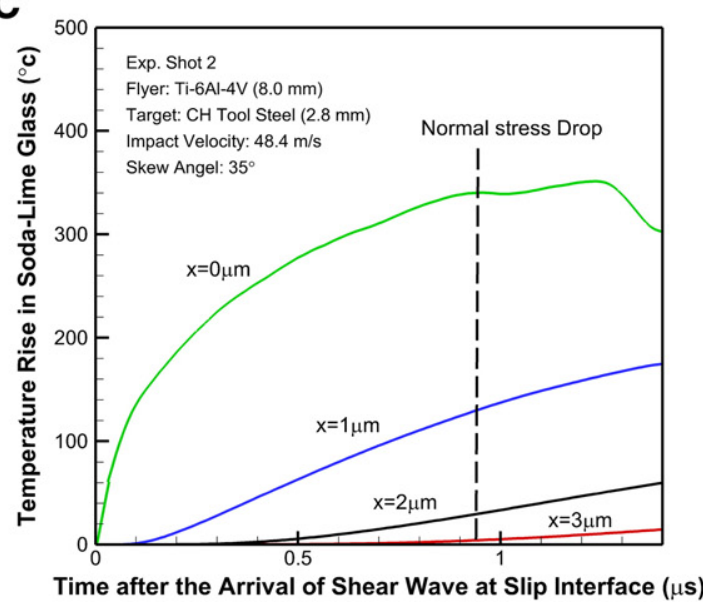

Fig. 3. (a) History of shear (friction) stress and interfacial slip velocity for Shot 2 . (b) History of interfacial slip velocity and coefficient of kinetic friction for Shot 2; (c) estimated temperature rise at the tribo-pair interface for Shot 2.

in a re-initiation of dramatic weakening and the interfacial shear stress falls precipitously to $8 \mathrm{MPa}$ and the corresponding slip velocity jumps to $38 \mathrm{~m} / \mathrm{s}$.

Fig. 2(c) shows the history of the coefficient of friction and interfacial slip velocity as a function of time for Shot 1 . Immediately after impact, the slip interface shows strong weakening with increasing slip and slip velocity during which the coefficient of friction falls
A

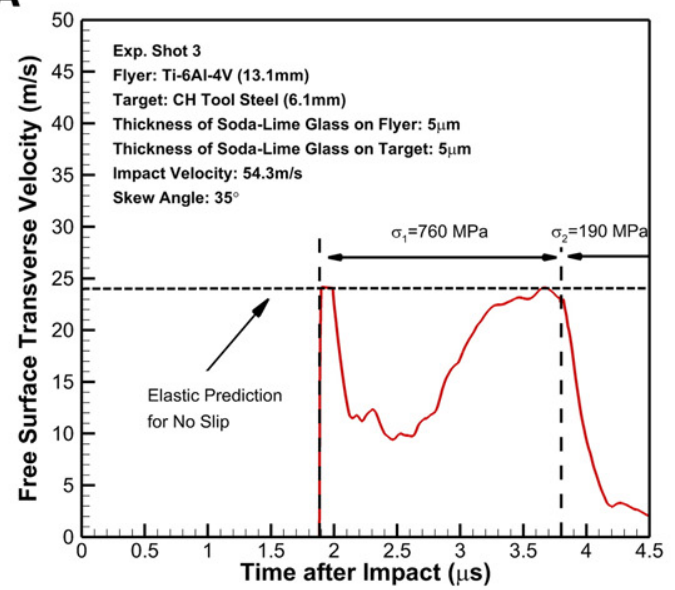

B

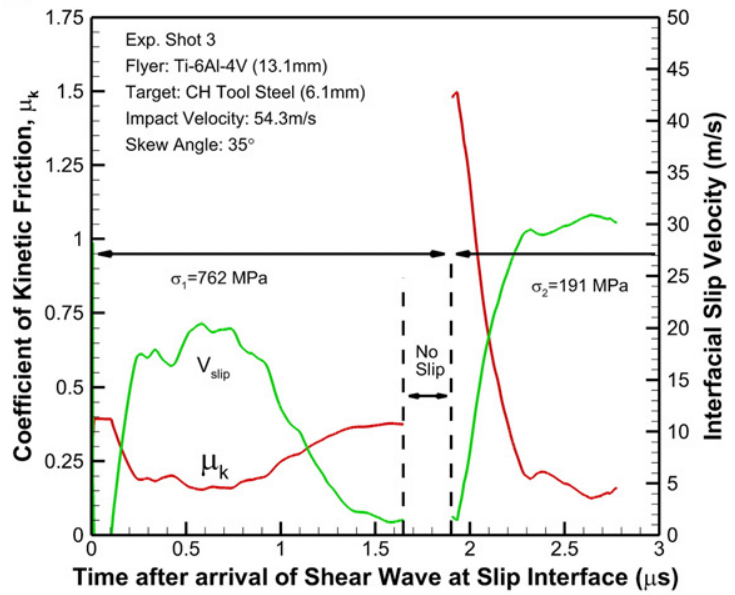

C

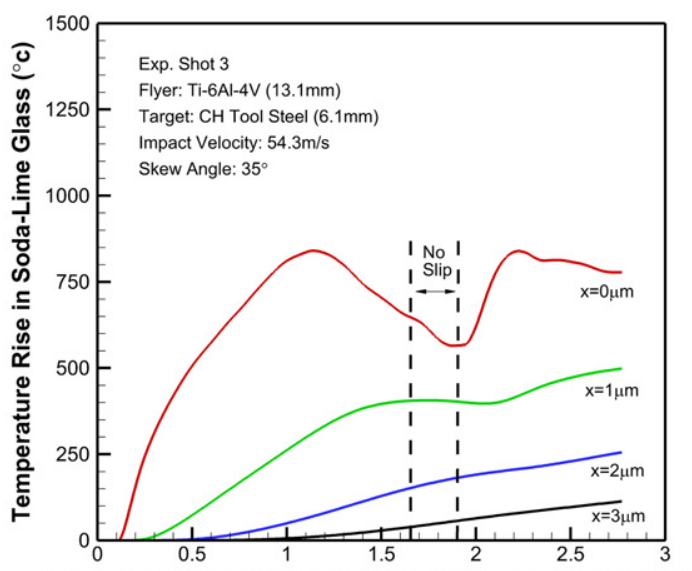

Time after Arrival of Shear wave at Slip Interface Impact ( $\mu$ s)

Fig. 4. (a) Transverse particle velocity history of the rear surface of the $\mathrm{CH}$ tool steel target plate for Shot 3; (b) history of interfacial slip velocity and coefficient of kinetic friction for Shot 3; (c) estimated temperature rise at the tribo-pair interface for Shot 3.

from ca. 0.1 to 0.05 . The slip velocity, during this time increases from $26 \mathrm{~m} / \mathrm{s}$ to $32 \mathrm{~m} / \mathrm{s}$. This weakening phase is followed by a strengthening phase, which can be seen as an increase in coefficient of friction from 0.05 to 0.08 with a corresponding decrease in slip velocity from $32 \mathrm{~m} / \mathrm{s}$ to $28 \mathrm{~m} / \mathrm{s}$.

At the beginning of State 2, the normal stress drops abruptly from $1.15 \mathrm{GPa}$ to $280 \mathrm{MPa}$; however, the corresponding drop in friction 
Table 2

Summary of experiments conducted on soda-lime glass in the present study.

\begin{tabular}{|c|c|c|c|c|c|}
\hline Shot \# & $\begin{array}{l}\text { Skew angle } \\
\theta \text {, deg }\end{array}$ & $\begin{array}{l}\text { Impact velocity } \\
\mathrm{V}, \mathrm{m} / \mathrm{s}\end{array}$ & $\begin{array}{l}\text { Flyer: Ti-6Al-4V } \\
(\mathrm{mm})\end{array}$ & $\begin{array}{l}\text { Target: } \mathrm{CH} \text { tool steel } \\
(\mathrm{mm})\end{array}$ & $\begin{array}{l}\text { Roughness of soda-lime } \\
\text { glass layer, } \mu \mathrm{m}\end{array}$ \\
\hline Shot 1 & 30 & 77.3 & 8.0 & 2.9 & 0.2 \\
\hline Shot 2 & 35 & 48.4 & 8.0 & 2.8 & 0.2 \\
\hline Shot 3 & 35 & 54.3 & 13.1 & 6.1 & 0.12 \\
\hline
\end{tabular}

stress is more gradual resulting in a spike (jump) in the coefficient of kinetic friction from 0.08 to approximately 0.3 and then drops back to 0.07 . During the transition from State 1 to State 2, the slip velocity increases rapidly from 30 to $38 \mathrm{~m} / \mathrm{s}$. Such spikes in coefficient of friction have previously been reported during transient metal-on-metal slip (Irfan and Prakash, 2000; Prakash, 1998; Prakash and Clifton, 1993; Ullah et al., 2007), and have been attributed to the memory of normal stress history at the slip interface. To the best of authors' knowledge, the experiments reported in here are the first to reveal such effects of normal stress in a rock analog material. As discussed earlier, deviations from the classical formulation of Coulomb friction of the type observed in these experiments allow models of rupture that incorporate a sudden alteration in normal stress (e.g. rupture along dissimilar material interfaces) to be well posed mathematically (Ranjith and Rice, 2001; Rice et al., 2001). In contrast, conventional slow (quasi-static) friction studies, with much less abrupt change of normal stress (Boettcher and Marone, 2004; Dieterich and Linker, 1992; Linker and Dieterich, 1992), suggest that shear strength changes on the same time-scale as the normal stress change, but changes only partly towards what it will ultimately evolve to after a few $\mu \mathrm{m}$ of further slip.

Fig. 2(d) shows the estimate for the temperature rise during the dynamic slip event. By assuming slip to occur between two semi-infinite glass plates, the average temperature rise at the tribo-pair interface during State 2 was estimated by solving the one-dimensional transient heat conduction equation (Eq. (17)). At the initiation of slip in State 1 considerable frictional heat is generated, and the interfacial temperature increases monotonically with time to about $825^{\circ} \mathrm{C}$. The diffusive nature of the solution is clearly evident from the sharp decay in the bulk temperatures with increasing distance perpendicular to the frictional interface. It is interesting to note that even though these estimated interfacial temperatures do not predict melting of the soda lime glass, they are still high enough to result in considerable softening of the glass films (glass transition temperature, $T_{g}$, of soda lime glass is $570{ }^{\circ} \mathrm{C}$; solidus to liquidus temperature $\sim 1000{ }^{\circ} \mathrm{C}$ ). It must be mentioned that these temperature rise distributions are an estimate of the actual global temperatures that can exist during the frictional sliding process. A number of assumptions have been made in arriving at these estimates: (a) the thermal properties of soda-lime glass are assumed to be constant at their room temperature values at all temperatures, and (b) all the interfacial frictional work is assumed to be converted to heat. The assumption that all the frictional work is converted to heat may lead to an overestimation of the actual interface temperature rise distribution. However, all inelastic processes during the slip process are expected to occur at the slip interface within a thin layer, the thickness of which is of the order surface roughness of the soda lime glass films. In view of these arguments, the computed temperature profiles are expected to represent the actual temperature distributions with acceptable level of confidence.

The experimental results for Shot 2 are shown in Fig. 3(a) to (c). The experiment was conducted at an impact velocity of $48.4 \mathrm{~m} / \mathrm{s}$ at a skew angle of $35^{\circ}$. By reducing the impact velocity when compared to that used in Shot 1, it is anticipated that less severe interfacial conditions (in terms of state of stress and temperature) will develop at the slip interface. Fig. 3(a) shows the shear stress and slip velocity as a function of time for Shot 2. Again, two distinct friction states are obtained in the experiment: State 1, which begins at the arrival of the shear wave at the slip interface and ends when the unloading (release) longitudinal wave arrives at the interface at $875 \mathrm{~ns}$, and State 2 which ends at ca. 1250 ns. The corresponding normal stress during States 1 and 2 were $680 \mathrm{MPa}$ and $170 \mathrm{MPa}$, respectively. During State 1, the interface shows dramatic slip and slip velocity weakening during which the shear stress at the interface falls from $90 \mathrm{MPa}$ to $55 \mathrm{MPa}$. The slip velocity during this phase increases from $17 \mathrm{~m} / \mathrm{s}$ to $22 \mathrm{~m} / \mathrm{s}$. At the end of this weakening phase, a second but more gradual weakening phase is observed, where the interfacial shear stress drops from $55 \mathrm{MPa}$ to $35 \mathrm{MPa}$ (by the end of State 1). The corresponding slip velocity increases from $22 \mathrm{~m} / \mathrm{s}$ to $24 \mathrm{~m} / \mathrm{s}$. The arrival of release wave results in a sudden drop in normal stress resulting in a corresponding decrease in shear stress to $30 \mathrm{MPa}$ while the slip velocity increases to $\sim 25 \mathrm{~m} / \mathrm{s}$. It is interesting to note that the weakening phase is not followed by a distinct strengthening phase, as was observed in Shot 1.

Fig. 3(b) shows the history of the coefficient of friction and interfacial slip velocity as a function of time for Shot 2 . Immediately after impact, during the first weakening phase, the coefficient of friction falls from approximately 0.14 to 0.09 . During this phase the slip velocity, increases from $17 \mathrm{~m} / \mathrm{s}$ to $22 \mathrm{~m} / \mathrm{s}$. This weakening phase is followed by a second weakening phase, during which the coefficient of kinetic friction decreases to 0.05 with an increase in slip velocity to $24 \mathrm{~m} / \mathrm{s}$. At the initiation of State 2, the normal stress drops abruptly from $680 \mathrm{MPa}$ to $170 \mathrm{MPa}$; however, the corresponding drop in shear stress is relatively slower and smaller, and results in a spike (jump) in the coefficient of kinetic friction to approximately 0.19 from 0.05 and then drops back to only 0.18 . It must be noted that the steady state level of the coefficient of friction immediately following the drop in normal stress for Shot 2 is much higher when compared to the level for Shot $1\left(\mu_{\mathrm{k} 2} / \mu_{\mathrm{k} 1}\right.$ for Shot $1 \sim 1$, while $\mu_{\mathrm{k} 2} / \mu_{\mathrm{k} 1}$ for Shot $\left.2 \sim 3.5\right)$. During the transition from State 1 to State 2, the interfacial slip velocity increases from $23 \mathrm{~m} / \mathrm{s}$ to $24 \mathrm{~m} / \mathrm{s}$.

Fig. 3(c) shows the estimated rise in temperature during the dynamic slip as a function of time after the arrival of shear wave at the slip interface. The maximum bulk temperature rise at the interface during State 1 is $340{ }^{\circ} \mathrm{C}$, while the maximum temperature reached in State 2 is $350{ }^{\circ} \mathrm{C}$. These temperatures are clearly below the glass transition temperature of soda-lime glass, and the weakening observed in State 1 can be clearly attributed to flash heating and local asperity melting during the slip event. Also, the relatively low bulk temperatures rule out the strengthening (healing) phase, as no significant melt patches are expected to develop at the slip interface. These melt patches are understood to lead to an increase in the effective contact area and subsequent slip strengthening (healing). Moreover, the higher levels of the coefficient of kinetic friction in State 2 for Shot 2 can be attributed to the state of the slip interface when the normal stress drop was introduced. In Shot 1, the slip interface was in a state of healing (strengthening) with interfacial temperature close to the solidus to liquidus transition temperature in soda lime glass when the normal stress was introduced, while the interface in Shot 2 shows weakening with relatively lower bulk interfacial temperatures (less than $T_{g}$ for soda lime glass) when the normal stress drop is introduced.

The experimental results for Shot 3 are shown in Fig. 4(a) to (c). The experiment was conducted at an impact velocity of $54.3 \mathrm{~m} / \mathrm{s}$ and a skew angle of $35^{\circ}$. It should be noted that the rms surface roughness of the soda-lime glass is $0.12 \mu \mathrm{m}$ when compared with 
$0.2 \mu \mathrm{m}$ for Shots 1 and 2 . In addition, for Shot 3, the thickness of the flyer and the target plates was changed so as to delay the arrival of the release wave from the free surface of the flyer plate. Fig. 4(a) shows the transverse component of the particle velocity history at the free surface of the $\mathrm{CH}$ tool-steel target plate. Also shown in the figure are the normal stress and the elastic prediction of the transverse component of the particle velocity for the case of no-slip at the interface. The no-slip particle velocity was obtained from the elastodynamic solution to the slip problem given by Eq. (12) with $V_{\text {slip }}$ set to zero on the LHS. In State 1 the normal stress is $762 \mathrm{MPa}$, while in State 2 the normal stress is $191 \mathrm{MPa}$. The arrival of shear wave at the free surface of the target plate occurs at approximately 1900 ns. With the arrival of the shear wave at the free surface of the target plate the transverse component of the particle velocity jumps to the no-slip predicted level of about $23 \mathrm{~m} / \mathrm{s}$. After a momentary stay at this no-slip level the transverse velocity falls precipitously to a level of about $10 \mathrm{~m} / \mathrm{s}$ before increasing again to a no slip level of $23 \mathrm{~m} / \mathrm{s}$. The transverse particle velocity stays at this no-slip level until the arrival of the unloading wave at the slip interface at which the transverse particle velocity level again falls to about $3 \mathrm{~m} / \mathrm{s}$.

Fig. 4(b) shows the history of the normal stress, coefficient of kinetic friction, and interfacial slip velocity as a function of time for Shot 3. Two distinct friction states are obtained in the experiments: State 1 which begins just after impact and ends at ca. 1900 ns, and State 2 which ends at ca. 2800 ns. During State 1 the normal stress at the friction interface is constant at $762 \mathrm{MPa}$ while the normal stress in State 2 is 191 MPa. During State 1, after a momentary initial stick, the interface shows abrupt slip and slip velocity weakening during which the coefficient of friction falls from 0.4 to $\sim 0.2$ in about 200 ns. The slip velocity during this time increases from no-slip to about $20 \mathrm{~m} / \mathrm{s}$. The weakening phase is followed by a distinct strengthening phase, during which the friction coefficient increases gradually to 0.4 , eventually leading to seizure of the interface. The seizure of the interface is confirmed by the transverse particle velocity which corresponds to the no-slip level predicted by Eq. (9). The slip velocity decreases monotonically from $20 \mathrm{~m} / \mathrm{s}$ to the no-slip level during this strengthening (healing) phase. It is interesting to note that, during State 1 , the coefficient of kinetic friction stays in the range of 0.2 and 0.4 (slip speeds $<20 \mathrm{~m} / \mathrm{s}$ ), which is much lower than those observed under quasi-static slip conditions ( $\mu \sim 0.6$ to 0.85 ) at slip speeds of $\leq 1 \mathrm{~mm} / \mathrm{s}$. The arrival of the unloading longitudinal wave at the slip (seized) interface occurs at $1900 \mathrm{~ns}$. At the arrival of the unloading longitudinal wave at the slip interface the normal stress drops abruptly from $762 \mathrm{MPa}$ to $191 \mathrm{MPa}$. This sudden alteration (drop) in normal stress leads to the re-initiation of slip at the frictional interface. It is interesting to note that the coefficient of kinetic friction at the re-initiation of frictional slip is as high as 1.5 , when compared to the coefficient of kinetic friction at the moment of interface seizure, which was 0.35 .

Fig. 4(c) shows an estimate for the temperature rise during the dynamic slip event. During state 1 , the maximum temperature rise attained at the frictional interface $(x=0)$ occurs during the strengthening phase (prior to the seizure of the interface) and is estimated to be about $900{ }^{\circ} \mathrm{C}$. The high temperature is consistent with the formation of melt patches at the interface, which are understood to promote healing of the slip interface, following the end of the weakening phase. As the slip velocity approaches the "no-slip" level (seizure of the slip interface), it results in a decrease in frictional power (and a corresponding drop in interfacial temperature), which promotes strengthening/healing of the slip interface. The interfacial temperature picks up again as slip is reinitiated at the frictional interface following the drop in normal stress.

The results of Shot 3 are consistent with those reported by several investigators including Hirose and Shimamoto (2005), who conducted a series of experiments on Indian gabbro at slip rates of $0.85-1.49 \mathrm{~m} / \mathrm{s}$ and normal stresses of $1.2-2.4 \mathrm{MPa}$ by using a rotary-shear apparatus. The experiments revealed two stages of slip weakening separated by a marked strengthening regime. By examination of microstructures of simulated fault zone under scanning electron microscopy (SEM) at different total slip displacements, they proposed that the initial slip weakening is due to the thermal weakening induced by flash heating at the asperity contacts and early stages of melting; this phase is followed by slip strengthening caused by the coalescence of melt patches into a thin molten layer, while the observed second slip-weakening was attributed to the growth of the molten interfacial layer during friction melting. The observed weakening followed by strengthening (healing) behavior suggests that a fault weakens markedly during co-seismic slip, but rapidly recovers its strength after the maximum velocity is reached. This evolution of friction is quite different from the simpler behavior assumed by many theoretical and numerical models of earthquake phenomena. Such models may need to be modified in light of these laboratory findings. As suggested by the researchers, the initial increase in friction observed in their experiments may act as a barrier to fault motion. This may stop small earthquakes from becoming larger and contribute to the observed variety of fault-slip patterns and earthquake magnitudes. Furthermore, the peak value of fault friction is likely to depend on slip-rate history, further encouraging slip complexity.

\section{Discussion and summary}

In recent years the emergence of the high-speed rotary shear experimental configuration has allowed researchers to reproduce the interfacial slip conditions in rocks encountered during earthquake slip, at least in terms of slip velocity (about $1 \mathrm{~m} / \mathrm{s}$ ) and slip (several meters for large magnitude earthquakes) but low normal stresses ( $<20 \mathrm{MPa}$; see Spray (1987, 2005), Tsutsumi and Shimamoto (1997), Mizoguchi and Fukuyama (2010), and Di Toro et al. (2011) for reviews) or in terms of slip (several meters) and normal stress (up to $112 \mathrm{MPa}$ ) but low slip velocity $(<5 \mathrm{~mm} / \mathrm{s})$ (e.g., Goldsby and Tullis (2002)).

The results of these studies on the frictional properties of intrusive rocks at co-seismic slip speeds have shown that rock melting occurs when a certain threshold combination of normal stress, sliding velocity and displacement is reached (Spray, 1987; Tsutsumi and Shimamoto, 1997). Once a melt layer is produced, the strength of the fault is determined by the viscosity of the melt and the strain rate in the melt. Although these experimental and theoretical studies have demonstrated that melt lubrication can be an efficient weakening mechanism details of the evolution of strength remains unsure, in particular owing to the relatively small range of normal stress and slip rates that earlier machines could reach. It should be noted that these experiments were performed under relatively low normal stresses $(<25 \mathrm{MPa})$ and without a good control on the acceleration and deceleration of the target slip velocity.

In the present study plate-impact pressure-shear friction experiments are employed to investigate the frictional resistance in a silicate-rich rock-analog material, i.e. soda lime glass, at interfacial conditions relevant during fault rupture. In these experiments the normal stress (in State 1) was in range of ca. $300 \mathrm{MPa}$ to $1000 \mathrm{MPa}$ with slip velocities as high as $40 \mathrm{~m} / \mathrm{s}$. At these relatively large normal stresses and slip velocities the frictional interface is expected to undergo large scale melting within hundreds of microns of slip distance. However, due to the relatively short slip distances (tens of microns) in the present experiments, the melting at the interface is restricted to a few isolated softened/molten patches, allowing us to better investigate the intrinsic slip resistance during glass-on-glass slip. In addition, by probing the slip behavior under the relatively high normal stress and slip rates, critical information on fault slip at relatively large seismogenic depths can be obtained, a condition that has been difficult to study experimentally using more conventional apparatus.

The results of the experiments indicate that a wide range of frictional slip conditions exist at the frictional interface: the interfacial 
conditions range from initial no-slip followed by slip and slip-rate weakening, strengthening, and seizure all during a single slip event. The coefficient of kinetic friction during the initial slip-rate weakening phase is much lower than $\mu \sim 0.6$ to 0.85 obtained at quasi-static slip rates $\leq 1 \mathrm{~mm} / \mathrm{s}$ (Byerlee (1978) and Dieterich (1978)), and is understood to be caused by thermal weakening due to flash heating at the asperity junctions.

An elementary model considering flash heating at asperity contacts had been proposed recently by Rice (2006). The model considers contacts of uniform size $L$, and hence life-time $L / V$, where $L$ is the slip needed to renew the asperity contact population, and $V$ is slip rate; and assumes that their shear strength remains at the room temperature value, $\tau_{C}$, until temperature has reached a critical value, $T_{\text {crit }}$, above which the weakened shear strength $\tau_{W}$ is assumed to has a negligibly small compared to its room temperature value $\tau_{C}$. The temperature rise of the asperities is estimated from a simple one-dimensional transient heat conduction equation, with heating power $\tau_{C} V$ per unit area at the sliding contact surface. Beeler et al. (2008) observed that a better fit of Rice's model to data showing strong rate-weakening of friction was to assume a small but non-negligible $\tau_{W}$ for $T_{a}>T_{\text {crit. }}$. The model thus defines a critical slip rate $V_{\text {crit }}$ such that there is no weakening if $V<V_{\text {crit }}$, but strong weakening if $V>V_{\text {crit }}$. That is, the friction coefficient $\mu$, which has the value $\mu_{0}$ at low slip rates and $\mu_{W}$ at high slip rates, is given in the following simple model

$\mu=\mu_{0}$ if $V<V_{\text {crit }}, \mu=\left(\mu_{0}-\mu_{W}\right) \frac{V_{\text {crit }}}{V}+\mu_{\mathrm{W}}$ if $V>V_{\text {crit }}$;

$V_{\text {crit }}=\alpha \frac{\pi}{L}\left[\frac{\rho c\left(T_{c r i t}-T_{b u l k}\right)}{\tau_{\mathrm{C}}}\right]^{2}$

where $\alpha$ is thermal diffusivity, $\rho c$ is heat capacity per unit volume.

Using Eqs. (19) and (20), a critical velocity of $V_{\text {crit }}=0.12 \mathrm{~m} / \mathrm{s}$ can been estimated for the onset of severe thermal weakening in glass and other geo-materials, by taking $L=5 \mu \mathrm{m}, \tau_{C}=3.0 \mathrm{GPa}$ and temperature range from ambient up to $\sim 900{ }^{\circ} \mathrm{C}$. The results presented in the present paper on rapid slip on rock-analog materials are indeed consistent with such an expected reduction in friction stress.

On the other hand, the increase in friction stress with slip observed in Shots 1 and 3 is understood to be due to slip and slip-rate dependent strengthening processes. It has also been argued that at intermediate to high slip rates where temperature increase by frictional heat becomes significant, not only velocity dependence but also temperature dependence of friction are important in the understanding of nucleation and propagation of rupture (Noda, 2008; Noda et al., 2009). Also, as noted earlier, the occurrence of strengthening indicates that frictional heating and temperature dependent friction within the rate weakening regime are important, which can lead to material softening and coalescence and solidification of melt patches on the slip interface that are eventually responsible for interface strengthening. This is further confirmed from the results derived from Shot 2 where slip occurs at bulk interfacial temperatures below the glass transition temperature of soda-lime glass (i.e. in the absence of melt patches at the slip interface), and thus show an absence of the slip strengthening phase. In particular, these experiments confirm the hypothesis that by reducing the stress (friction) power at the slip interface the interface will undergo weakening due to flash heating with an absence of healing (strengthening), which requires development of melt patches at the slip interface. Strictly speaking, it is quite difficult to identify if melting occurs or not during the experiments because partial melting in soda-lime glass might occur without any luminous materials outside the sample. Here, "non-melting" condition means that we could not observe any visible melting during the experiments. We do not deny a possibility of small scale melting where some patches on the surfaces start to melt.
An intriguing result from the present experiments has been the very low friction coefficients observed in Shots 1 and 2 when compared to Shot 3 in the initial phase of the pressure and shear impact loading. In experiment Shots 1 and 2 the friction coefficient, at the beginning of State 1 , was as low as 0.08 and 0.14 , respectively, while for Shot 3 it was 0.4. A possible reason for these observations in Shots 1 and 2 may be due to the initiation of slip immediately following impact, and represents the frictional resistance during the highly transient (acceleration) phase at the slip interface. On the other hand for Shot 3 the interface is initially near the "no slip" condition for a short time before initiation of slip occurs at the interface.

Even though the present experiments do not involve meters of slip distance, the rate of frictional work done is high (due to the high normal stress and high slip velocities) and they reproduce the general strengthening-weakening-strengthening features of frictional slip observed in rotary shear type experiments. This suggests that the interfacial response is strongly slip rate and normal stress dependent. Moreover, from these experiments, we find that the slip-weakening distance is of the order of only a few tens of microns. These relatively small slip distances are in agreement with theoretical considerations presented by (Niemeijer et al., 2011) where normal stress and slip velocity together control the critical slip weakening distance. In further support of this, Brantut et al. (2008) have studied the frictional properties of natural kaolinite-bearing gouge samples from the Median Tectonic Line (SW Japan) using a high-velocity rotary shear apparatus. Dramatic slip weakening was observed in their experiments at slip rates of ca. $1 \mathrm{~m} / \mathrm{s}$. The inferred critical slip weakening distance values ranged from a few centimeters at $10 \mathrm{MPa}$ normal stress to as low as a few hundreds of microns at $100 \mathrm{MPa}$ normal stress. As a comparison, at normal stresses ranging from 0.3 to $1.3 \mathrm{MPa}$, a critical slip-weakening distance of the order of 1 to $10 \mathrm{~m}$ was inferred. These relatively low values of the slip weakening distances at relatively high normal stresses were consistent with those observed in the experiments conducted in the present study, and are expected to play an important role in governing rupture dynamics at large seismogenic depths and at high sliding rates.

In addition, our results on fault weakening followed by healing verify the proposition that faults may be weak dynamically but statically strong. The rapid transition from high static friction to low dynamic friction through dependence on slip rate may also be one of the possible reasons for the absence of melting in many mature faults that have sustained hundreds of meters of slip. If the fault strength does not weaken during seismic slip, the temperature rise due to slipping for several meters at slip rates around $1 \mathrm{~m} / \mathrm{s}$ and under normal stresses that are of the order of 100-200 MPa will be of the order of thousands of degrees, sufficient to cause complete melting of the rocks existing in the fault zone (Noda and Lapusta, 2010; Noda et al., 2009; Rice, 2006). However, no significant evidence of melting has been found in many mature faults (Aagaard and Heaton, 2008; Rice, 2006). In this regard, fault healing and decelerating fault motion are understood to be intrinsic fault properties that favor pulse-like (short slip duration) rupture propagation (Heaton, 1990; Nielsen and Madariaga, 2003; Zheng and Rice, 1998).

In addition to the observation related to slip and slip velocity weakening and strengthening, in the present investigation plate-impact friction experiments were conducted that involve sudden alteration in normal stress at the slip interface. These experiments were designed such that in Shots 1 and 2 the sudden drop in normal stress was introduced during the slip and slip velocity weakening phase and prior to the initiation of slip strengthening, while in Shot 3 the drop in normal stress occurred just after the strengthening phase during the seized state of the interface. These experiments are the first of their type in rock-analog materials and confirm the existence of memory effects of the normal stress history that is similar to that observed previously during metal-on-metal slip. These results in rock-analog materials have implications for fault strength during static and dynamic stress transfer 
at fault junctions, the interaction of multiple faults in complex structural settings, and for dynamic fault rupture as slip propagates, or attempts to propagate, through such complex fault geometries and/or dis-similar materials. In turn, these results could have implications for the ability of ruptures to propagate across geometrical boundaries in fault systems, where rapid changes in normal stress are expected.

The above findings can be qualitatively understood within the existing framework of what are termed as rate- and state dependent friction laws. In that framework, friction depends on slip rate and on an evolving state variable. Modifying the framework by adjusting the state variable and its evolution equation would allow the incorporation of the experimental results into numerical models in a way that is consistent with previous experimental work. Several factors that were not considered in the experiments in the present study may significantly affect fault friction. These include the role of fluids permeating fault zones, melting of fault materials under higher compression and variations in material properties across the fault. Establishing whether these factors are indeed significant and how they interact with each other requires further imaginative and sophisticated laboratory studies that reproduce the range of conditions expected in fault zones at seismogenic depths and will be reported in future publications.

\section{Acknowledgments}

The authors would like to acknowledge the financial support of National Science Foundation Earth Division through grants EAR: 0710975 and EAR: 0810083 for conducting this research. The authors would also like to acknowledge the Major Research Instrumentation Award CMS-0079458 by the National Science Foundation for the acquisition of the Multi-beam VALYN VISAR used in the present experiments.

\section{References}

Aagaard, B.T., Heaton, T.H., 2008. Constraining fault constitutive behavior with slip and stress heterogeneity. Journal of Geophysical Research-Solid Earth 113.

Achenbach, J.D., 1973. Wave Propagation in Elastic Solids. North-Holland, Amsterdam.

Adams, G.G., 1995. Self excited oscillations of two elastic half-spaces sliding with a constant coefficient of friction. Journal of Applied Mechanics 62, 867-872.

Andrews, D.J., Ben-Zion, Y., 1997. Wrinkle-like slip pulse on a fault between different materials. Journal of Geophysical Research 102, 553-571.

Archard, J.F., 1958. The temperature of rubbing surfaces. Wear 2, 438-455.

Ashby, M.F., Abulawi, J., Kong, H.S., 1991. Temperature maps for frictional heating in dry sliding. Tribology Transactions 34, 577-587.

Barber, J.R., 1976. Some thermoelastic contact problems involving frictional heating. Quarterly Journal of Mechanics and Applied Mathematics 29, 1-13.

Beeler, N.M., Tullis, T.E., 1996. Self-healing slip pulses in dynamic rupture models due to velocity-dependent strength. Bulletin of the Seismological Society of America $86,1130-1148$.

Beeler, N.M., Tullis, T.E., Weeks, J.D., 1994. The roles of time and displacement in the evolution effect in rock friction. Geophysical Research Letters 21, 1987-1990.

Beeler, N.M., Tullis, T.E., Goldsby, D.L., 2008. Constitutive relationships and physical basis of fault strength due to flash heating. Journal of Geophysical Research-Solid Earth 113

Ben-Zion, Y., 2001. Dynamic ruptures in recent models of earthquake faults. Journal of Mechanics and Physics of Solids 49, 2209-2244.

Blanpied, M., Tullis, T.E., 1986. Stability and behavior of frictional sliding with a two state variable constitutive law. Pure and Applied Geophysics 124, 415-444.

Blanpied, M.L., Tullis, T.E., Weeks, J.D., 1998. Effects of slip, slip rate, and shear heating on the friction of granite. Journal of Geophysical Research-Solid Earth 103, 489-511.

Boettcher, M.S., Marone, C., 2004. Effects of normal stress variation on the strength and stability of creeping faults. Journal of Geophysical Research-Solid Earth 109.

Bowden, F.P., Thomas, P.H., 1954. The surface temperature of sliding solids. Proceedings of Royal Society of London A 223, 29-36.

Brantut, N., Schubnel, A., Rouzaud, J.N., Brunet, F., Shimamoto, T., 2008. High-velocity frictional properties of a clay-bearing fault gouge and implications for earthquake mechanics. Journal of Geophysical Research-Solid Earth 113.

Brune, J.N., 1970. Tectonic stress and spectra of seismic shear waves from earthquakes. Journal of Geophysical Research 75, 4997-5009.

Byerlee, J.D., 1978. Friction of rocks. Pure and Applied Geophysics 116, 615-626.

Cochard, A., Madariaga, R., 1994. Dynamic faulting under rate-dependent friction. Pure and Applied Geophysics 142, 419-445.

Cochard, A., Rice, J.R., 2000. Fault rupture between dissimilar materials: ill-posedness, regularization, and slip-pulse response. Journal of Geophysical Research 105, 891-907.
Di Toro, G., Goldsby, D.L., Tullis, T.E., 2004. Friction falls towards zero in quartz rock as slip velocity approaches seismic rates. Nature 427, 436-439.

Di Toro, G., Hirose, T., Nielsen, S., Pennacchioni, G., Shimamoto, T., 2006. Natural and experimental evidence of melt lubrication of faults during earthquakes. Science 311, 647-649.

Di Toro, G., Han, R., Hirose, T., De Paola, N., Nielsen, S., Mizoguchi, K., Ferri, F., Cocco, M., Shimamoto, T., 2011. Fault lubrication during earthquakes. Nature 471, 494-+.

Dieterich, J.H., 1978. Time dependent friction and mechanics of stick-slip. Pure and Applied Geophysics 116, 668-675.

Dieterich, J.H., 1979. Modeling of rock friction: I, experimental results and constitutive equations. Journal of Geophysical Research 84, 2161-2168.

Dieterich, J.H., 1981. Constitutive properties of faults with simulated gouge. In: Carter, N.L., Friedman, M., Logan, J.M., Stearns, D.W. (Eds.), Mechanical Behavior of Crustal Rocks: the Handin Volume, Geophysics Monograph Series. American Geophysical Union, Washington D.C., pp. 103-120.

Dieterich, J.H., Conrad, G., 1984. Effect of humidity on time- and velocity-dependent friction in rocks. Journal of Geophysical Research 89, 4196-4202.

Dieterich, J.H., Kilgore, B.D., 1994. Direct observation of frictional contacts: new insights for state-dependent properties. Pure and Applied Geophysics 143, 283-302.

Dieterich, J.H., Kilgore, B., 1996. Implications of fault constitutive properties for earthquake prediction. Proceedings of the National Academy of Sciences of the United States of America 93, 3787-3794.

Dieterich, J.H., Linker, M.F., 1992. Fault stability under conditions of variable normal stress. Geophysical Research Letters 19, 1691-1694.

Ettles, C.M.M., 1986. The thermal control of friction at high sliding speeds. Journal of Tribology-Transactions of the Asme 108, 98-104.

Fukuyama, E., Mizoguchi, K., 2010. Constitutive parameters for earthquake rupture dynamics based on high-velocity friction tests with variable slip rates. International Journal of Fracture 163, 15-26.

Goldsby, D., Tullis, T.E., 2002. Low frictional strength of quartz rocks at subseismic slip rates. Geophysical Research Letters 29, 1844, http://dx.doi.org/10.1029/2002GL015240.

Harris, R.A., Day, S.M., 1997. Effects of a low-velocity zone on a dynamic rupture. Bulletin of the Seismological Society of America 87, 1267-1280.

Harris, R.A., Archuleta, R.J., Day, S.M., 1991. Fault steps and the dynamic rupture process - 2-D numerical simulations of a spontaneously propagating shear fracture. Geophysical Research Letters 18, 893-896.

Heaton, T.H., 1990. Evidence for and implications of self-healing pulses of slip in earthquake rupture. Physics of the Earth and Planetary Interiors 64, 1-20.

Hirose, T., Shimamoto, T., 2005. Growth of a molten zone as a mechanism of slip weakening of simulated faults in gabbro during frictional melting. Journal of Geophysical Research 110, B05202, http://dx.doi.org/10.1029/2004JB003207.

Hong, T.C., Marone, C., 2005. Effects of normal stress perturbations on the frictional properties of simulated faults. Geochemistry, Geophysics, Geosystems 6.

Irfan, M.A., Prakash, V., 1994. Contact temperatures during sliding in pressure shear impact. Proceedings Society of Experimental Mechanics Conference. SEM, Bethel, CT, pp. 173-182. Baltimore, MD.

Irfan, M.A., Prakash, V., 2000. Time resolved friction during dry sliding of metal on metal. International Journal of Solids and Structures 37, 2859-2882.

Kame, N., Rice, J.R., Dmowska, R., 2003. Effects of prestress state and rupture velocity on dynamic fault branching. Journal of Geophysical Research-Solid Earth 108.

Kilgore, B.D., Blanpied, M.L., Dieterich, J.H., 1993. Velocity dependent friction of granite over a wide-range of conditions. Geophysical Research Letters 20, 903-906.

Kitajima, H., Chester, F.M., Chester, J.S., 2011. Dynamic weakening of gouge layers in high-speed shear experiments: assessment of temperature-dependent friction, thermal pressurization, and flash heating. Journal of Geophysical Research-Solid Earth 116.

Kuhlmann-Wilsdorf, D., 1985. Flash temperatures due to friction and joule heat at asperity contact. Wear 105, 187-198.

Kumar, P., Clifton, R.J., 1977. Optical alignment of impact faces for plate impact experiments. Journal of Applied Physics 48, 1366-1367.

Lapusta, N., Rice, J., 2003. Low-heat and low-stress fault operation in earthquake models of statically strong but dynamically weak faults. Eos Transactions AGU 84 (Fall Meet. Suppl., Abstract S51B-02)

Lim, S.C., Ashby, M.F., 1987. Wear mechanism maps. Acta Metallurgica 35, 1-24.

Lim, S.C., Ashby, M.F., Brunton, J.H., 1989. The effects of sliding conditions on the dry friction of metals. Acta Materialia 37, 767-772.

Linker, M.F., Dieterich, J.H., 1992. Effects of variable normal stress on rock friction: observations and constitutive equations. Journal of Geophysical Research 97, 4923-4940.

Liou, N.S., Okada, M., Prakash, V., 2004. Formation of molten metal films during metalon-metal slip under extreme interfacial conditions. Journal of the Mechanics and Physics of Solids 52, 2025-2056.

Marone, C., 1998. Laboratory-derived friction laws and their application to seismic faulting. Annual Review Earth and Planetary Science 26, 643-696.

Marone, C., Raleigh, C.B., Scholz, C.H., 1990. Frictional behavior and constitutive modeling of simulated fault gouge. Journal of Geophysical Research 95, 7007-7025.

Mazurin, O.V., 1993. Handbook of Glass Data. Elsevier, Amsterdam.

Mizoguchi, K., Fukuyama, E., 2010. Laboratory measurements of rock friction at subseismic slip velocities. International Journal of Rock Mechanics and Mining Sciences 47, 1363-1371.

Mizoguchi, K., Hirose, T., Shimamoto, T., Fukuyama, E., 2009. High-velocity frictional behavior and microstructure evolution of fault gouge obtained from Nojima fault, southwest Japan. Tectonophysics 471, 285-296.

Molinari, A., Estrin, Y., Mercier, S., 1999. Dependence of the coefficient of friction on the sliding conditions in the high velocity range. Journal of Tribology-Transactions of the Asme 121, 35-41. 
Nielsen, S., Madariaga, R., 2003. On the self-healing fracture mode. Bulletin of the Seismological Society of America 93, 2375-2388.

Nielsen, S., Mosca, P., Giberti, G., Di Toro, G., Hirose, T., Shimamoto, T., 2010. On the transient behavior of frictional melt during seismic slip. Journal of Geophysical Research 115 .

Niemeijer, A., Di Toro, G., Nielsen, S., Di Felice, F., 2011. Frictional melting of gabbro under extreme experimental conditions of normal stress, acceleration, and sliding velocity. Journal of Geophysical Research 116.

Noda, H., 2008. Frictional constitutive law at intermediate slip rates accounting for flash heating and thermally activated slip process. Journal of Geophysical Research-Solid Earth 113.

Noda, H., Lapusta, N., 2010. Three-dimensional earthquake sequence simulations with evolving temperature and pore pressure due to shear heating: effect of heterogeneous hydraulic diffusivity. Journal of Geophysical Research-Solid Earth 115.

Noda, H., Dunham, E.M., Rice, J.R., 2009. Earthquake ruptures with thermal weakening and the operation of major faults at low overall stress levels. Journal of Geophysical Research-Solid Earth 114

Okada, M., Liou, N.-S., Prakash, V., Miyoshi, K., 2001. Tribology of high speed metal-onmetal sliding at near-melt and fully-melt interfacial temperatures. Wear 249, 672-686.

Okada, M., Liou, N.S., Prakash, V., 2002. Dynamic shearing resistance of molten metal films at high pressures. Experimental Mechanics 42 (2), 161-171.

Okubo, P.G., Dieterich, J.H., 1986. State variable fault constitutive relations for dynamic slip. Earthquake Source Mechanics AGU Geophysical Monograph Series 37, 25-35.

Olsson, W.M., 1988. The effect of normal stress history on rock friction. In: Cundall, P.A Sterling, R.L., Starfield, A.M. (Eds.), Key Questions in Rock Mechanics: Proceedings of the 29th U.S. Symposium A. A. Balkema, Rotterdam, pp. 111-117.

Perrin, G., Rice, J.R., Zheng, G., 1995. Self healing slip pulse on a frictional surface. Journal of the Mechanics and Physics of Solids 43, 1461-1495.

Poliakov, A.N.B., Dmowska, R., Rice, J.R., 2002. Dynamic shear rupture interactions with fault bends and off-axis secondary faulting. Journal of Geophysical Research-Solid Earth 107.

Prakash, V., 1995. A pressure-shear plate impact experiment for investigating transient friction. Experimental Mechanics 35, 329-336.

Prakash, V., 1998. Frictional response of sliding interfaces subjected to time varying normal pressures. Journal of Tribology 120, 97-102.

Prakash, V., 2009. Rate and state variable friction laws: estimation of model parameters for slip dependence at coseismic slip rates. Journal of Applied Physics 106, 123513

Prakash, V., Clifton, R.J., 1993. Time resolved dynamic friction measurements in pres sure-shear. In: Ramesh, K.T. (Ed.), Experimental Techniques in the Dynamics of Deformable Bodies. ASME, New York, pp. 33-47.

Ranjith, K., Rice, J.R., 2001. Slip dynamics at an interface between dissimilar materials. Journal of the Mechanics and Physics of Solids 49, 341-361.

Rempel, A.W., Weaver, S.L., 2008. A model for flash weakening by asperity melting during high-speed earthquake slip. Journal of Geophysical Research-Solid Earth 113

Rice, J.R., 1999. Flash heating at asperity contacts and rate-dependent friction. Eos Transactions of the American Geophysical Union 80, F681.

Rice, J.R., 2006. Heating and weakening of faults during earthquake slip. Journal of Geophysical Research-Solid Earth 111.

Rice, J.R., Cocco, M., 2007. Seismic fault rheology and earthquake dynamics. In: Handy, M.R., G.H., Hovius, N. (Eds.), Tectonic Faults: Agents of Change on a Dynamic Earth. The MIT Press, Cambridge, MA, USA, pp. 99-138.
Rice, J.R., Lapusta, N., Ranjith, K., 2001. Rate and state dependent friction and the stability of sliding between elastically deformable solids. Journal of the Mechanics and Physics of Solids 49, 1865-1898.

Ruina, A., 1980. Frictional Laws and Instabilities-a Quasistatic analysis of Some Dry Frictional Behavior. Brown University.

Ruina, A., 1983. Slip stability and state variable friction laws. Journal of Geophysical Research 88, 10359-10370.

Scholz, C.H., 1998. Earthquakes and friction laws. Nature 243, 37-42.

Scholz, C.H., 2002. The Mechanics of Earthquakes and Faulting, 2nd ed. Cambridge University Press, Cambridge, UK.

Scholz, C.H., Molnar, P., Johnson, T., 1972. Detailed studies of fricitonal sliding of granite and implications for earthquake mechanism. Journal of Geophysical Research 77, 6392-6404.

Simões, F.M.F., Martins, J.A.C., 1998. Instability and ill-posedness in some friction problems. International Journal of Engineering Science 36, 1265-1293.

Sone, H., Shimamoto, T., 2009. Frictional resistance of faults during accelerating and decelerating earthquake slip. Nature Geoscience 2, 705-708.

Spray, J.G., 1987. Artificial generation of pseudotachylite using friction welding apparatus: simulation of melting on a fault plane. Journal of Structural Geology 9, 49-60.

Spray, J.G., 2005. Evidence for melt lubrication during large earthquakes. Geophysical Research Letters 32, http://dx.doi.org/10.1029/2004GL022293.

Tsutsumi, A., Shimamoto, T., 1997. High-velocity frictional properties of gabbro. Geophysical Research Letters 24, 699-702.

Tullis, T.E., 1988. Rock friction constitutive behavior from laboratory experiments and its implications for an earthquake prediction field monitoring program. Pure and Applied Geophysics 126, 555-588.

Tullis, T.E., Weeks, J.D., 1986. Constitutive behavior and stability of frictional sliding of granite. Pure and Applied Geophysics 124, 383-414.

Ullah, H., Irfan, M.A., Prakash, V., 2007. State and rate dependent friction laws for modeling high-speed frictional slip at metal-on-metal interfaces. Journal of Tribology $129,17-22$.

Weeks, J.D., Beeler, N.M., Tullis, T.E., 1991. Frictional behavior: glass is like a rock. Eos Transactions AGU 72, 457-458 Fall Meeting Abs. Supp.

Weertman, J., 1980. Unstable slippage across a fault that separates elastic media of different elastic constants. Journal of Geophysical Research 85, 1455-1461.

Xia, K.W., Rosakis, A.J., Kanamori, H., Rice, J.R., 2005. Laboratory earthquakes along inhomogeneous faults: directionality and supershear. Science 308, 681-684.

Yuan, F., Prakash, V., 2008a. Slip weakening in rocks and analog materials at co-seismic slip rates. Journal of the Mechanics and Physics of Solids 56, 542-560.

Yuan, F., Prakash, V., 2008b. Use of a modified torsional Kolsky bar to study frictional slip resistance in rock analog materials at co-seismic slip rates. International Journal of Solids and Structures 45, 4247-4263.

Yuan, F., Liou, N.-S., Prakash, V., 2009. High-speed frictional slip at metal-on-metal interfaces. International Journal of Plasticity 25, 612-634.

Zheng, G., Rice, J.R., 1998. Conditions under which velocity-weakening friction allows a self-healing versus a cracklike mode of rupture. Bulletin of the Seismological Society of America 88, 1466-1483. 